$\mathbb{T}$ periodica polytechnica

\author{
Transportation Engineering \\ 36/1-2 (2008) $105+110$ \\ doi: 10.3311/pp.tr.2008-1-2.19 \\ web: http://www.pp.bme.hu/tr \\ (c) Periodica Polytechnica 2008
}

RESEARCH ARTICLE

\section{Impact of transportation on} environment

\author{
Katalin Tánczos / Ádám Török
}

Received 2007-03-03

\begin{abstract}
Our aim in this article is to prove the connection of $\mathrm{CO}_{2}$ emission and climate change and to estimate the $\mathrm{CO}_{2}$ emission of the transport sector. We have to clarify the emission of the transport sector in order to get information of externalities, what is a further step to a sustainable society. The sustainable development is a development, where the pace of technical development, the satisfaction of increasing supply and the raw materials and resources of Earth are poised so that the rate of living and opportunities of the next generations need not to be worse. One of the most emphasized goals of the transport policy of the European Union is sustainable mobility. For this reason transportation systems must be developed and standardized, the effectiveness of transportation service must be increased, while the environmental pollution must be decreased or prevented. Decoupling motorization from environmental pollution is the task for engineers. Decoupling the increase of mobility from economic activity is a task for economists.
\end{abstract}

\section{Keywords}

climate change $\cdot$ diesel oil $\cdot$ petrol $\cdot$ decoupling $\cdot$ motorization .

\section{Katalin Tánczos}

Department of Transport Economics, BME, H-1111 Budapest Bertalan L. u. 2., Hungary

\section{Ádám Török}

Department of Transport Economics, BME, H-1111 Budapest Bertalan L. u. 2., Hungary

e-mail: atorok@kgazd.bme.hu

\section{Introduction}

The EU's target of reducing greenhouse gas emissions by $20 \%$ by 2020 is only realistic if the emissions from the transport sector are drastically reduced. This was the main message of today's conference "Fighting climate change - The potential of rail transport", which brought together 150 stakeholders from the transport sector and high-level politicians to discuss the contribution of the railways to environment policy.

In the long history of human development, mobility has always played a decisive role, while in our days transportation has already become one of the most important means to meet human needs. In the member countries of the European Union, the free mobility of people, goods and services are already considered today as a basic collective achievement that can ensure the freedom of mobility for everybody without discrimination including the right of settlement in the member countries, the working permit anywhere, the availability of goods produced in faraway places, or the accessibility to any of the sales- and procurement markets.

As a matter of fact, mobility requires the existence and efficient operation of appropriate transportation systems which are built up from sophisticated subsystems which are composed of infrastructural networks, vehicles as well as installed pieces of equipment. Those are designed to keep up the undisturbed vehicular and pedestrian traffic processes, or else the passenger and freight flow by means of integrated control systems.

Naturally, people are the factors playing a decisive role in transportation and mobility, and take part in transportation in the quality either of pedestrians, passengers or drivers, as active or passive factors of the traffic flow and as the potential producers or users of goods, as well as service providers. People through their own transportation habits, their activities and their positions occupied in the social-economic spheres of activity will influence the development of the demands for goods and passenger transport either directly or indirectly, and through their decisions they will determine the operational efficiency of the transportation processes initiated by meeting the demands. The mobility demand ensuring the access or accessibility is considered to be an inherent feature of globalization processes, which 
is destined to guarantee the dynamic balance of the more advantageous utility value/price ratio developing under the competitive conditions (terms) of market supply and demand.

However, communication and transportation enabling the free mobility of passenger and freight transport is considered to be not only one of the main motive power of social-economic development but at the same time it is one of the notable detrimental factors of natural and built environment. This statement is justified by the fact that the liability to accidents, the air pollution and noise impacts especially from the part of vehicular road traffic, as well as the delay caused by traffic jams, the impairment of health, the deteriorating effect on biodiversity will involve wide-range consequences both in space and time, which in turn will exert an adverse influence on the quality of human life. Therefore the reasonable restriction of mobility bringing about detrimental effects should be considered as a common social interest.

In addition to the functions of mobility described above, the social cohesive function of mobility should also be taken into consideration, which can be observed especially in connection with the land use and regional planning. The advantageous communication, transportation possibilities will play a decisive role not only in the selection of sites by business enterprises and the allocation of distributive centres, but the existing and planned mobility conditions themselves will have a considerable influence on the selection of dwelling- and workplace, as well as on the location of shopping and recreation centres. As a matter of fact, the influential systems will have a mutual impact on one another, since the spatial arrangement of the above mentioned establishments of traffic generation or attraction, respectively, will retroact on the traffic flow developed between those places, and as a consequence it will influence the development of town and settlement structures and their functional efficiency, too.

The promotion of economic growth, the increased environmental and health protection as well as meeting the complex and conflicting requirements to contribute to the social cohesion and the balanced spatial development, at the same time, will concentrate on creating and providing continuously the conditions of sustainable mobility. By this approach, the maximization of social welfare is targeted with the simultaneous achievement of free movement (mobility), so that the feasibility conditions of the prospective continuous human development would not be endangered. The attainment of the above goals requires devoted, deliberate and consistent transportation policy control not only on a nation-wide scale but also on the level of the European Union and to some extent even in global measures. The set of means to implement the common transportation policy equally contains the integrated development of infrastructure, as well as measures to encourage the updating of organizations and their activities for the sake of more efficient utilization of the existing capacities, further on marketing activities supporting the development of mobility culture more reasonable from social point of view, besides the harmonization of taxation systems, and eco- nomic and financial regulations encouraging the decrease of energy consumption and in turn, abating environmental load, as well as interventions to restrict the development of additional mobility demands (sporadically and intermittently) [1].

\section{Linkage between economic activity, motorization and air pollution}

There is a great disharmony between the modern society that requires more and more mobility and the common will of protecting our environment. The increase of economic activity - presented by GDP [USD/persons/year] causes mobility demand - presented by motorization [PCU ${ }^{1} / 1000$ inhabitant] and increases in environmental pollution - presented by [tC/inhabitant/year]

The time series data were available from International Monetary Found, Energy Information Administration, and Eurostat (For the modelling data of Austria, Belgium, Finland, France, Greece, Netherlands, Luxemburg, Germany, Italy, Portugal, Spain, Hungary between 1993 and 2003 have been used). We have made the average by nations to get the trend of the phenomenon. Regarding the correlation analysis, there is a strong correlation between the GDP and motorization ( $r=0.7877)$, and in the linear regression analysis we got the result that the elasticity of GDP to motorisation is: 0.0094 (Fig. 1).

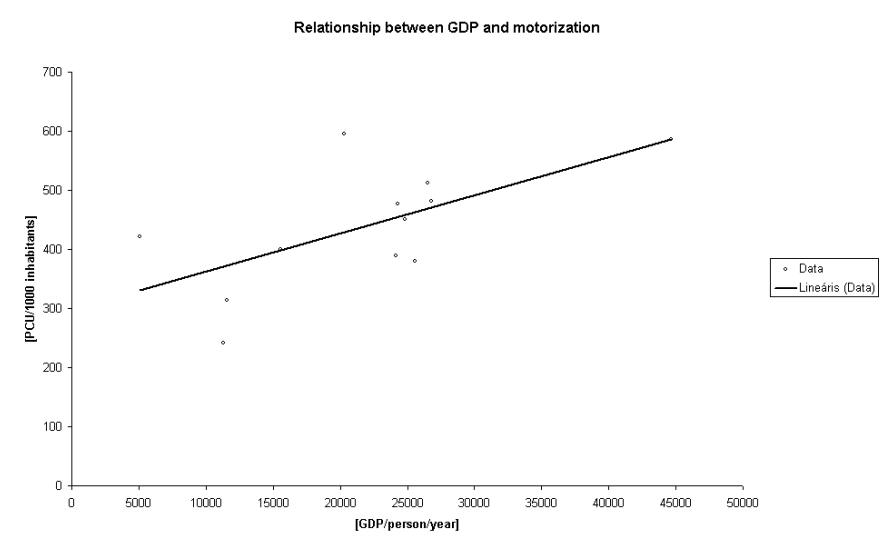

Fig. 1. Relationship between GDP and motorization

We have found that there is a strong correlation between economic activity and environmental pollution. That means that the increasing economic activity has positive effect on standards of living and negative effect of environmental pollution as well (Fig. 2).

We have found that the elasticity of environmental pollution on motorization is: 0,019 . That means $1 \%$ change in motorization in the observed countries causes $0,019 \%$ change in total carbon emission (Fig. 3] [3].

We have modelled (1) the linear relationship between economic activity, transport activity and air pollution (Fig. 4):

$$
A P=f(G D P, M O T(G D P))
$$

\footnotetext{
${ }^{1}$ PCU: passenger car unit
} 
Relationship between GDP and air pollution

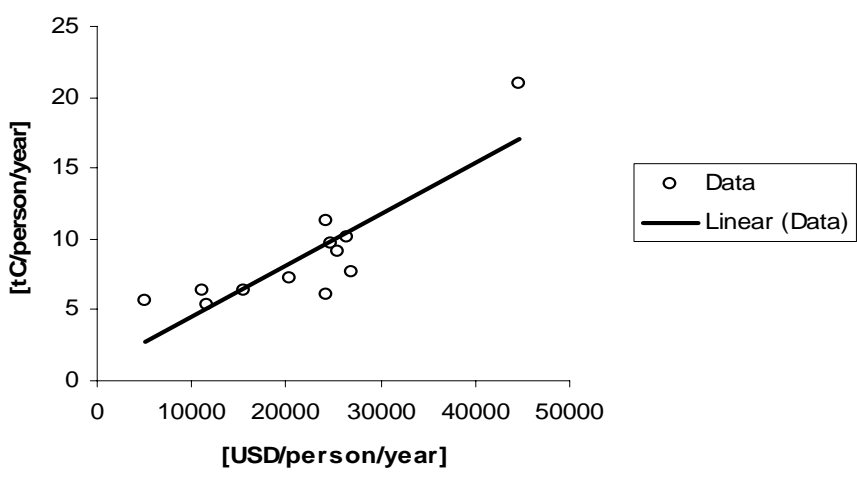

Fig. 2. Relation between GDP and air pollution

Realtionship between motorisation and air pollution

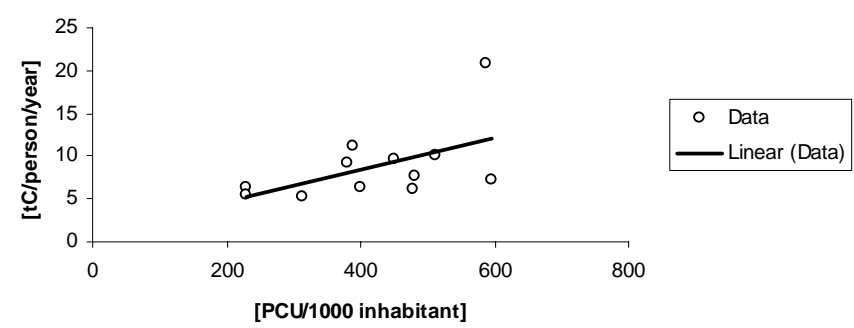

Fig. 3. Relationship between motorization and air pollution

Where:

AP: $\quad$ Air Pollution

GDP: Gross Domestic Product - economic activity

MOT: Motorization - transport activity

Growth in economic activity and growth in transport activity are strongly correlated. The causal relationships between the two may not be well understood; i.e., there may be uncertainty as to whether economic activity causes transport activity or transport activity causes economic activity (or both occur). Whatever the causal relationships, if any, decoupling the two would be desirable so that economic growth continues but transport growth does not, so as a result of decoupling economic growth continues but environmental pollution growth does not.

We have also modelled (2) the linear relationship after the decoupling between the economic activity, mobility and air pollution, where there were no correlation between economic activity and mobility (Fig. 5):

$$
A P=f(G D P, M O T)
$$

Where:

AP: Air Pollution

GDP: Gross Domestic Product - economic activity

MOT: Motorization - transport activity

One solution for decoupling the motorization from environmental pollution would be the usage of alternative energy sources, biofuels.

There is a strong relation between economic activity and motorization. Although until now it has been unclear, weather the increase of economic activity affects motorization or the

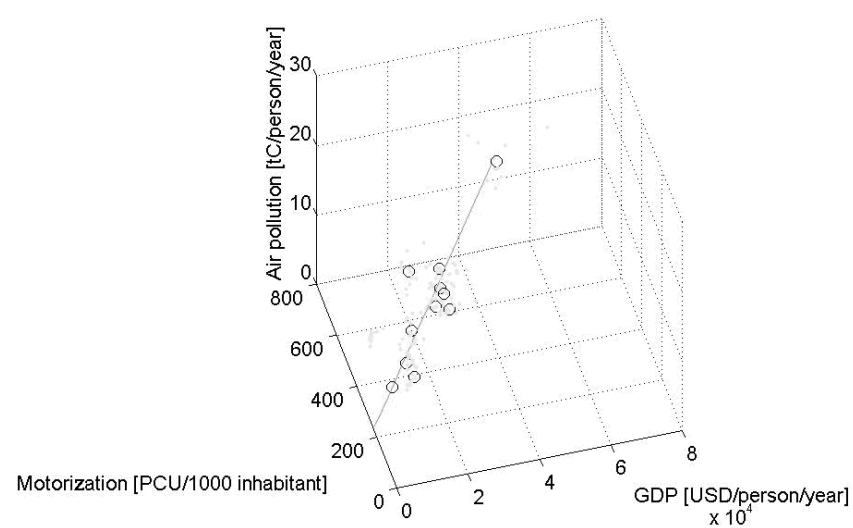

Fig. 4. Relationship between economic activity, motorization and air pollution

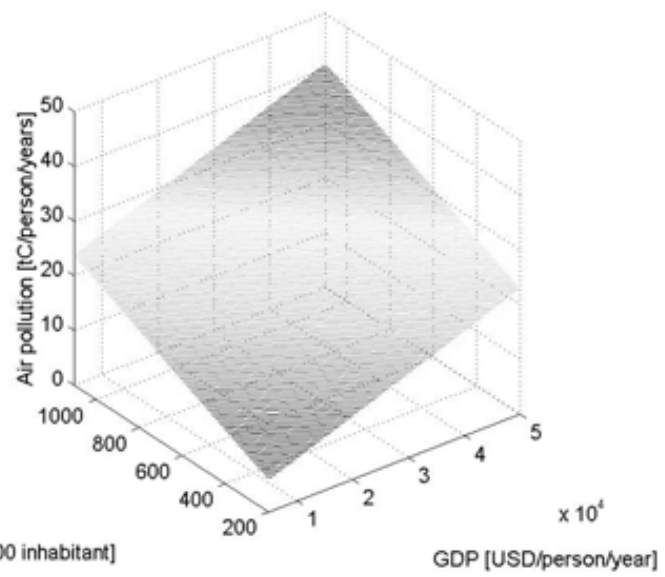

Fig. 5. Complex analysis of relationship of economic activity, motorization and air pollution after decoupling

increase of transport demand induces more economic activity. One effect is clear, the increase of motorization affects our environment, and there is a loop back, our environment has an effect on transportation.

After we have proved the necessity of the examination of emission in transport sector, we try in this article to estimate the $\mathrm{CO}_{2}$ emission of the transport sector in Hungary. We have to clarify the emission of the transport sector in order to get information on externalities, as a further step to sustainable society.

Nature gave humanity a stable base of living and gave almost infinite supply to reserve on Earth. In early ages humanity made changes to the environment with early technology, but globally it was not detectable. The motorization has been developed so dynamically that the air, soil, water pollutions are considerable to the amounts of air, soil, water of Earth. Transportation cannot be degenerated, as a part of the production chain. Societies are horizontally and vertically differential. The manpower, the stock, the semi-finished and finished products must be transported.

One of the most emphasized goals of the transport policy of the European Union is sustainable mobility. For this reason transportation systems must be developed and standardized, the effectiveness of transportation service must be increased, while the environmental pollution must be decreased or prevented. Externalities according to the EU guideline should be internalized 
and indicated in the cost of transportation [3].

\section{Fuel consumption of the transport sector of Hungary}

The majority of the energy we use in the transport sector in Hungary is based on oil, a non-renewable fossil fuel. The base of estimation method is that we assume that there is perfect burning, although we know that in reality just less $\mathrm{CO}_{2}$ can be produced, because there is no perfect burning. In our model we assume that for the $\mathrm{C}$ and $\mathrm{H}$ ratio of petrol we can use octane:

$$
\mathrm{C}_{8} \mathrm{H}_{18}+\frac{25}{2} \mathrm{O}_{2} \rightarrow 8 \mathrm{CO}_{2}+9 \mathrm{H}_{2} \mathrm{O}
$$

For the $\mathrm{C}$ and $\mathrm{H}$ ratio of gasoline we can use:

$$
\mathrm{C}_{14} \mathrm{H}_{30}+\frac{43}{2} \mathrm{O}_{2} \rightarrow 14 \mathrm{CO}_{2}+15 \mathrm{H}_{2} \mathrm{O}
$$

That means, from $1 \mathrm{~mol}$ that is $114 \mathrm{~g}$ of petrol there will be after perfect burning $8 \mathrm{~mol}$ that is $352 \mathrm{~g}$ carbon dioxide. From 1 mol, that is $198 \mathrm{~g}$ of gasoline there will be after perfect burning $14 \mathrm{~mol}$ that is $616 \mathrm{~g}$ carbon dioxide. If we take into account the density of petrol and gasoline we can calculate the maximum amount of $\mathrm{CO}_{2}$ when 1 liter of petrol or gasoline has been burnt.

Comparis on of fuel cons umption and emiss ion of carbon dioxide of pass anger cars in Hungary
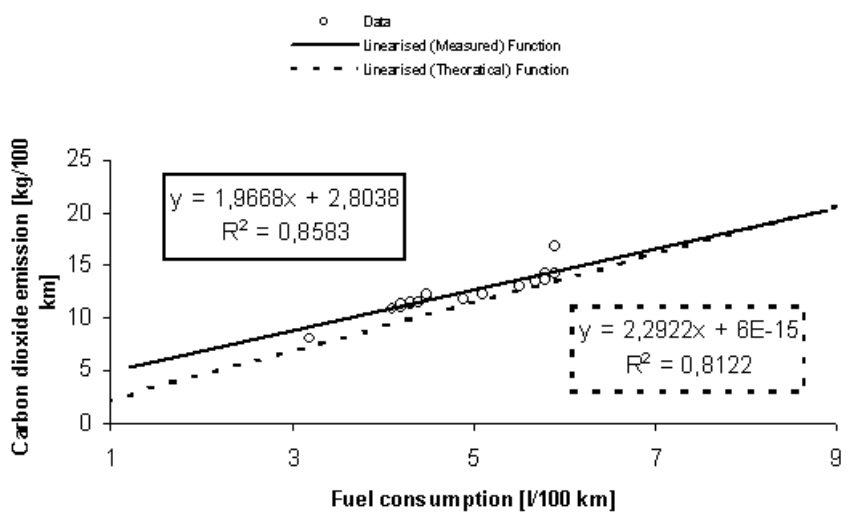

Fig. 6. Relation between the fuel consumption and carbon dioxide emission

Tab. 1. Estimation of carbon dioxide emission when burning petrol or diesel oil

\begin{tabular}{lcc}
\hline & Fuel [l] & $\mathrm{CO}_{2}$ emission[kg] \\
\hline Petrol & 1 & 2,161 \\
Diesel oil & 1 & 2,489 \\
\hline
\end{tabular}

We consider that Hungary has a fuel consumption that can be seen in Table 2 .

And diesel oil consumption that can be seen in Table 2 .

From this we can calculate that in 2003 Hungary had the total of 10.5 megatons carbon dioxide emission.
Tab. 2. Change of petrol consumption in time in Hungary [kilotons]

\begin{tabular}{ccccc}
\hline Quality (RON) & $\mathbf{2 0 0 0}$ & $\mathbf{2 0 0 1}$ & $\mathbf{2 0 0 2}$ & $\mathbf{2 0 0 3}$ \\
\hline 91 & 175 & 142 & 111 & 80 \\
95 & 927 & 1022 & 1062 & 1187 \\
98 & 231 & 208 & 176 & 165 \\
Total & 1333 & 1372 & 1349 & 1432 \\
\hline
\end{tabular}

Tab. 3. Change of diesel oil consumption in time in Hungary [kilotons]

\begin{tabular}{lllll}
\hline & 2000 & 2001 & 2002 & 2003 \\
\hline Diesel oil for motors & 1837 & 1908 & 1995 & 1951 \\
\hline
\end{tabular}

\section{External costs of climate change of transport sector in Hungary}

As it can be seen from Fig. 7 the number of Hungarian vehicles has slightly increased both in the case of petrol and gasoline driven vehicles. There was a slight increase in gasoline and petrol consumption as well, but the gasoline usage was nearly $50 \%$ higher because of the higher consumption level of HGVs. As it can be seen there had been a slight increase in $\mathrm{CO}_{2}$ emission as well.
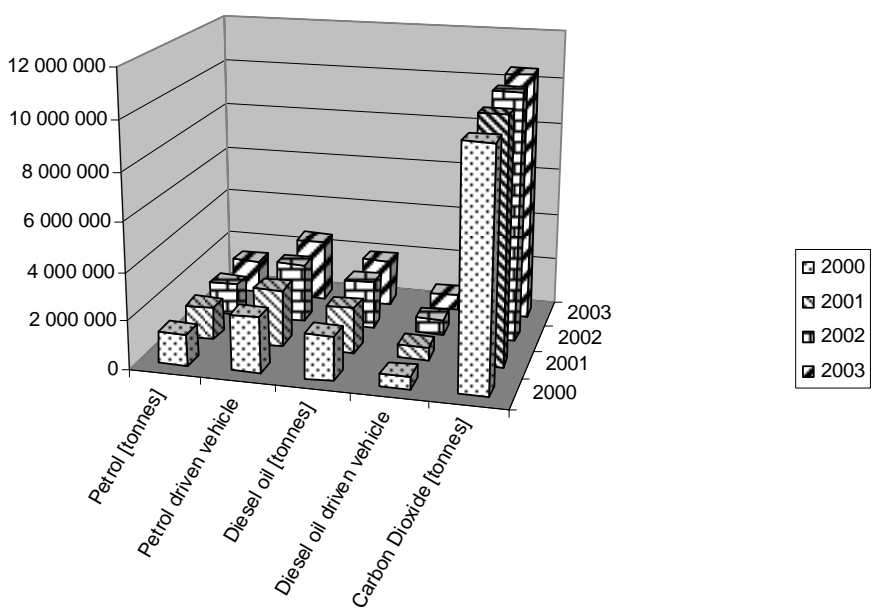

Fig. 7. Fuel consumption, emission and set of road transport sector in Hungary

We calculated the external cost of transport sector of Hungary according to EU climate researches. The method of calculating costs due to the emission of greenhouse gases (usually expressed as $\mathrm{CO}_{2}$ equivalents) basically consists of multiplying the amount of $\mathrm{CO}_{2}$ equivalents emitted by a cost factor. Due to the global scale of the damage caused, there is no difference how and where in Europe the emissions of greenhouse gases take place.

As it can be seen in Fig. 8 there is a slight increase in the cost of emitted carbon dioxide in Hungary. It can be explained by the increasing cost factor, and the increasing emitted gas, due to the increase of number of vehicles in Hungary, as we are using more cars, and even more fuel to satisfy our higher requirements of mobility. Although there are nearly the same amount of people "moving" in the country with nearly the same old cars. 


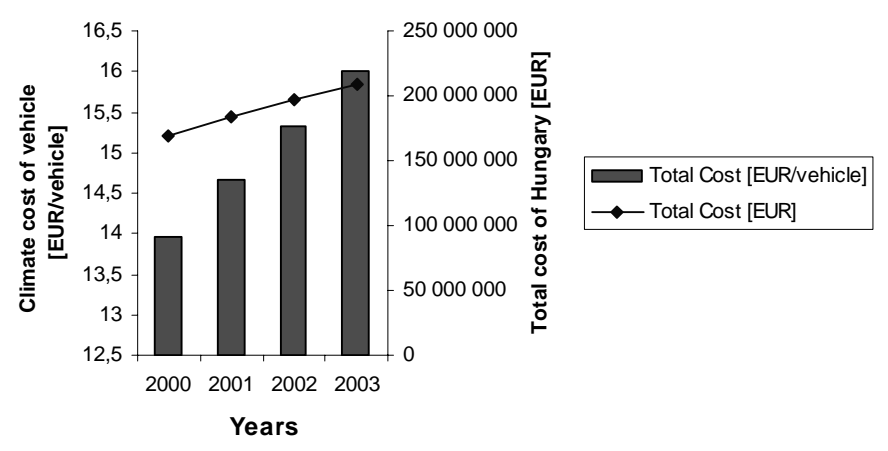

Fig. 8. Carbon dioxide emission in Hungary

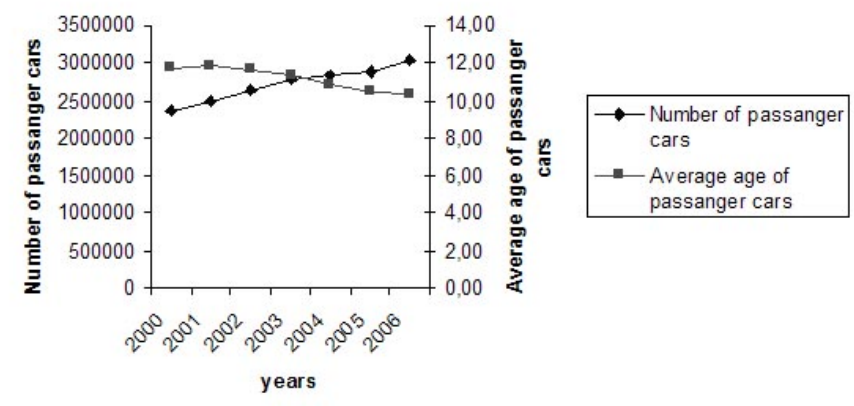

Fig. 9. Average age and number of passenger cars in Hungary

Now that we have monetized the cost of the effect, there should be the identification of the emitters. As it is caused by the road transportation, by using and burning fuel, the cost should be allocated to the fuel. In an economical sense this could be special taxation for the environment, with a common, social and political will to protect the nature.

But nowadays even the European taxation regimes that are connected to the fuel usage are not supporting the sustainable transportation or the maintenance of nature. There are scientifical approaches, EU funded research and development projects that clearly describe that solution [2]. Even in Hungary we started a national research and development project about climate change and about national climate change strategy.

There should be an equitable system for fuel using. That not only includes the parameter of used fuel, but the efficiency of burning as well. In road transport sector, this two parameter can be described by the EURO environmental group (the higher group means higher efficiency, as have lower limits of emission) and engine displacement as relevant parameter of fuel usage. (There is a high correlation between engine displacement and fuel consumption, $\mathbf{R}^{2}=0,62$ ). Generally $\mathbf{C}$ matrix with this assumption would be:

$$
\mathbf{C =}=\begin{array}{lll}
c_{11} & c_{1 j} & c_{1 n} \\
c_{i 1} & c_{i j} & c_{i n} \\
c_{m 1} & c_{m j} & c_{m n}
\end{array}
$$

where $c_{i j}$ is the number of thousands of passenger cars in EURO $i$ category and in category $j$ in engine displacement (Based on EUROSTAT categories: [until $1399 \mathrm{~cm}^{3} ; 1400-1999 \mathrm{~cm}^{3}$; from $2000 \mathrm{~cm}^{3}$ )). For Hungary, that $\mathbf{C}$ matrix would be in 2005 (see
(6) and Fig. 10,:

$$
\begin{array}{rlll} 
& 39 & 23 & 3 \\
\mathbf{C}_{\text {Hungary }, 2005}= & 80 & 166 & 25 \\
705 & 410 & 7 \\
620 & 360 & 53
\end{array}
$$

This could be bases of an equitable system, and it is in synchrony with the latest EU researches. Our paper aims to identify the macro economical cost of sector of road transportation in Hungary [4].

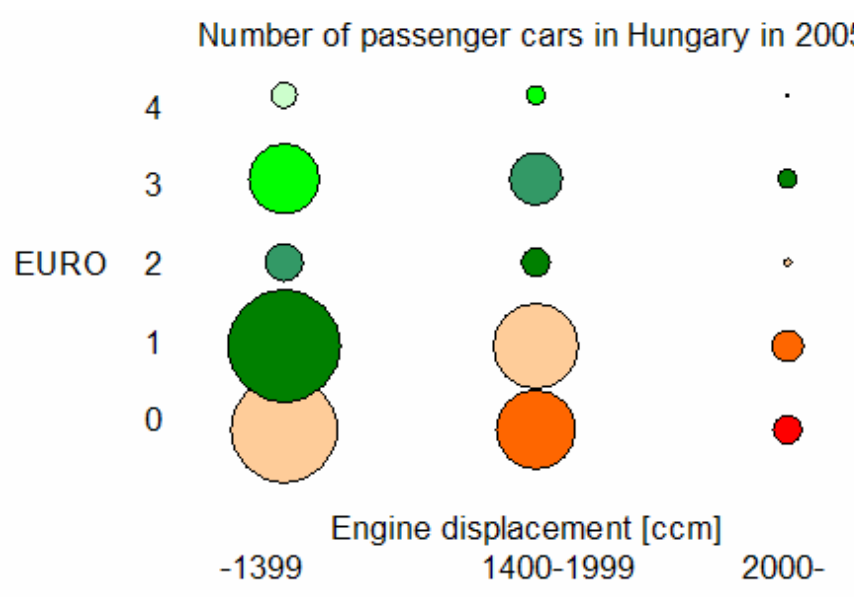

Fig. 10. Number of passenger cars in Hungary in 2005

\section{Summary}

There is a common, social will to protect the Earth and the environment. Climate change causes the crescendo of climate extremity in Hungary. There is a strong connection between environment and road transportation. Road transportation affects environment by emitting pollutants and greenhouse gases, but environment also affects road transportation through climate change. In this point of view transportation has to meet many challenges. It has to fulfil the challenge of environment, society and economy. Transport energy is a major cause of environmental pollution adding to the greenhouse effect with about $25 \%$ of total $\mathrm{CO}_{2}$ emission (Fig. 11) resulting from fossil fuel use.

\section{$\mathrm{CO}_{2}$ emission caused by humanity}

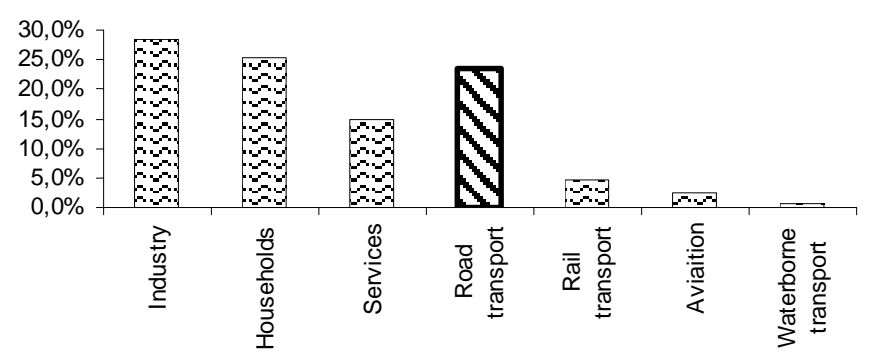

Fig. 12. Carbon dioxide emission caused by humanity

As there are so many international and national scientific hard and soft solutions for decreasing the emitted gases, yet even in 
Fig. 11. Average atmospherical $\mathrm{CO}_{2}$ and average Earth temperature complex time series [3]

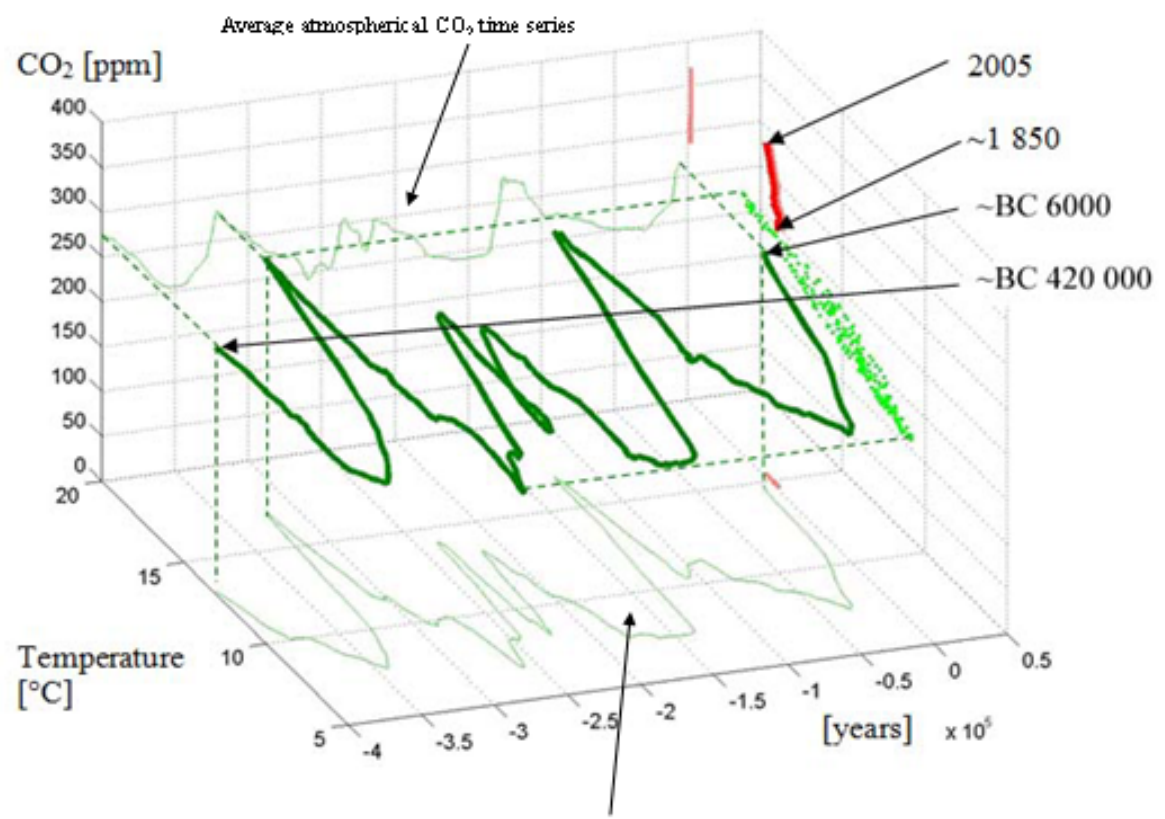

Average temperature time series
Europe there are only 1-2 solutions staring to work (car sharing, carpooling).

Vehicle emissions also cause increased levels of photochemical smog and carbon monoxide. The keys to substantially reducing the damaging effect of greenhouse gas emissions in the transport sector are [1]:

- choosing to minimize our petrol consumption and reliance on private vehicle use,

- the widespread use of alternative transport fuels.

It is an important aim to present authentically and make the public aware of all the features, favourable and adverse effects or consequences, respectively, of mobility as a secondary demand inherent in the social-economic activity so that the sustainability conditions are ensured in the long run, too.

Although the rapid development of technology geared by competition, the telematic solutions utilizing the results of innovative research will considerably contribute to the increase of transportation demand lagging behind the pace of economic growth, nevertheless the world-wide, intensive growth of mobility should be taken into account. Joint society-wide effort and consistent measures are required as harmonized both on international and national levels, as well as on regional and local ones in order to maintain a more environment-conscious human behaviour, and to persuade people to accept - either deliberately or forced by economic measures - the long-term mobility conditions which serve for the attainment of strategic goals and are more advantageous from social point of view. Wolfgang Tiefensee, German Federal Minister of Transport, Building and Urban Affairs and Head of the Council of the EU for Transport, quoted the example of Germany. "In my country, the introduction of road tolls in 2005 has clearly improved the capacity usage of trucks; in the same period of time, the volumes of goods transported by rail have significantly increased," he said. He also underlined that rail transport can only accommodate the growing transport needs of European citizens if there is sufficient infrastructure investment available. According to him, road tolls should be used for these investments.

\section{References}

1 Tánczos K, Eu-compatible transportation infrastructure - expectations and possibilities. Hungary at the turn of millennium., Strategic research at the Academy of Sciences contained in volume "Transportation and accession to the European Union", 1999, pp. 45-65.

2 Tánczos K, Török Á, The linkage of climate change and energy consumption of Hungary in the road transportation sector, Transport Journal 22, no. 2, 134-138.

3 Török Á, Climate change and road transportation sector, CEMEPE, Conference on Environmental Management, Engineering, Planning and Economics, Unknown Month 24, pp. 2569-2574.

4 Tánczos K, Török Á, Kosztyó Á, Sustainability of energy management of transport sector in Hungary, IYCE 2007(International Young Conference on Energetics). 